\title{
SEMBLANZA: GONZALO FIGUEROA YÁÑEZ, JURISTA PIONERO EN LA INVESTIGACIÓN Y ENSEÑANZA DEL DERECHO
}

\author{
GONZALO FIGUEROA YAÑEZ, PIONEER \\ JURIST IN RESEARCH AND TEACHING OF LAW
}

\author{
GONZALO FIGUEROA YAÑEZ, JURISTE \\ PIONNIER DANS LA RECHERCHE ET \\ L'ENSEIGNEMENT DU DROIT
}

\section{Sebastián Flores Díaz*}

Cuando hablamos de abogacía aparecen los abogados y los juristas. Abogados son quienes se dedican a la representación o asesoramiento de clientes. Sin embargo, los juristas van más allá de la profesión jurídica, dedicándose al conocimiento profundo de las ciencias jurídicas y sociales. Por lo mismo, su sinónimo más cercano es "jurisconsulto" o "persona dedicada al estudio e interpretación del Derecho". Aunque abogado y jurista parecieran significar lo mismo, también las veleidades del lenguaje sitúan vocablos como rábula o tinterillo como sinónimos.

Parafraseando a Gabriela Mistral, todos queremos ser juristas, pues entendemos que es la etapa superior de la profesión. Cuando pensamos en dicha etapa superior, uno de los nombres que aparecen es el de Gonzalo Figueroa, jurista, maestro, escritor, y también Director de nuestra Escuela de Postgrado de la Facultad de Derecho de la Universidad de Chile.

El relato de su vida nos lleva a recorrer ese duro camino hacia las metas. Hombre que sus cercanos describen como trabajador incansable, consiguió en vida un lugar entre las figuras prominentes de las ciencias jurídicas. Su interés por las diferentes áreas de las humanidades nos permite decir con propiedad que don Gonzalo era un jurista de tomo y lomo. Ellas iban desde la filosofía hasta la sociología, pasando por el arte y la política. Demócrata convencido, hacía dialogar las humanidades en sus trabajos, para interpretar y explicar las instituciones jurídicas.

Abogado. Licenciado en Ciencias Jurídicas y Sociales de la Universidad de Chile. Magíster (C) en Derecho Público de la Universidad de Chile. Investigador de la Escuela de Postgrado de la Facultad de Derecho de la Universidad de Chile. 


\section{Su VIDA}

Don Gonzalo nació el 12 de febrero de 1929. Compartía así su natalicio con otros acontecimientos históricos, como las fundaciones de Santiago en 1541, la de Valdivia en 1552, y la de Puerto Montt en 1853. Como recuerda Antonio PEDRALS, estos hechos son "sucesos que representan un avance cronológico hacia el Sur. Y, al hablar, de Gonzalo, hombre globalizado [...] no puedo olvidar que el poeta ha dicho que "la brújula del alma está marcando el Sur"1.

Sus primeros estudios los realizó en el Colegio La Maisonnette, institución fundada por su madre, doña Gabriela Yáñez. Según cuenta Jorge TAPIA “don Gonzalo consideraba que la vocación educadora de la madre, le fue trasmitida genéticamente". . Como el mismo recuerda, el colegio fue el refugio de perseguidos, como los judíos que llegaban escapando de los nazis, y los exiliados españoles de la guerra ${ }^{3}$. Enfatizó que La Maisonnette "ofrecía el cariño no discriminatorio que esos niños esperaban y negaba las barreras religiosas, políticas o raciales" , agregando que el establecimiento "resolvió ampliar su vocación de igualdad a los hijos de padres separados o anulados y vueltos a casar"s.

Continuó sus estudios en The Grange School, donde ingresó a los 11 años, en 1940. Fue ahí donde afirmo sus creencias libertarias. El profesor señaló que los pequeños como él eran los "esclavos" de los estudiantes "grandes", y por ende, debían preparar el teatro de operaciones para sus juegos de guerra de piedras. El padre de don Gonzalo, don Jorge Figueroa, le señaló que: "la esclavitud era el más grande oprobio que un humano podía cometer contra otro, que constituía una práctica inaceptable, contra la cual debia rebelarme"'.

A los 17 años ingresó a la Facultad de Derecho de la Universidad de Chile. Señala que ahí conoció el mundo real ${ }^{7}$. En ese año, 1946, se uniría al Cuerpo de Bomberos. Ingresó a la Primera Compañía de Santiago -la misma que acogió sus restos cuando partió de este mundo-. En dicha institución, el profesor recordaba que "pude desarrollar mis ansias de servicio público en un ambiente de compañerismo y amistad. Con el correr de los años, me convertí en un

\footnotetext{
Pedrals, Antonio. “Gonzalo Figueroa Yáñez, algunos recuerdos personales”. En Fundación Fernando Fueyo LaNERI. Estudios de Derecho Privado. Libro homenaje al profesor Gonzalo Figueroa Yánez. Santiago: Editorial Jurídica de Chile, 2008,

2 TAPIA, Jorge. “Gonzalo Figueroa Yáñez: educador y reformador”. En Fundación Fernando Fueyo LANeri. Estudios de Derecho Privado. Libro homenaje al profesor Gonzalo Figueroa Yánez. Santiago: Editorial Jurídica de Chile, 2008 , p. 15.

Figueroa Yáñez, Gonzalo. Memorias de mis últimos 200 años. Santiago: Editorial Andrés Bello, 2009, pp. 192-193.

Figueró YÁÑez (2009), p. 224.

Ibídem.

FigueroA YÁÑez (2009), p. 234.

Figueroa YÁÑez (2009), p. 266.
} p. 23. 
bombero verdaderamente fanático, serví en la mayoría de los cargos tanto de dirección como de mando, y por más de diez años me desempeñé como Superintendente". Sin embargo, la vocación académica se hacía presente. En 1951, a la par con sus estudios de derecho, ingresó a estudiar filosofía al entonces Instituto Pedagógico de la Universidad de Chile.

Según constatan los mismos estudiantes, don Gonzalo fue uno de los académicos con más años en la Facultad. El profesor Figueroa Yáñez inició su actividad académica en tercer año de derecho como alumno ayudante. Su carrera como docente propiamente tal, comenzó en la Escuela de Ciencias Políticas y Administrativas de la Universidad en el año 1959. Ahí impartió clases de Derecho Internacional Privado. Y en 1962, se integraría como profesor en la Facultad de Derecho. Por esos años ingresaría a la Orden Masónica.

Como parte del proyecto del International Legal Center y las Facultades de Derecho de la Universidad de Chile, Católica de Valparaíso y Concepción, asistió al seminario sobre metodología de la enseñanza e investigación jurídicas. En el año 1967 partió a Stanford y posteriormente a la Universidad de California - Los Angeles. Luego de este seminario, su visión de la pedagogía universitaria sería distinta. TAPIA señala que don Gonzalo no entró en el Programa con el objeto de ser un pionero en la innovación de la didáctica universitaria ${ }^{9}$. El mismo TAPIA comenta que el periplo fue la oportunidad para casarse con su mujer, Luz María Edwards ${ }^{10}$.

Al volver a Chile, nació la idea de formar un instituto. En mayo de 1969, ese proyecto se materializó en el Instituto de Docencia e Investigación Jurídicas. El profesor Figueroa Yáñez fue el secretario ejecutivo desde su creación hasta su disolución en 1975. TAPIA señala que el Instituto capacitó a 314 profesores, elaborando también numerosos textos y un Boletín ${ }^{11}$. El Instituto intentó, con relativo éxito, combinar la teoría jurídica con la praxis del Derecho. Don Gonzalo sostenía que los estudiantes de leyes debían estar encarcelados al menos una semana para saber en qué consistía la privación de libertad. Recuerda Manuel GonZÁlez que el profesor Figueroa Yáñez "incursionada [...] de manera revolucionaria para el ambiente de la época, en el denominado "método socrático de materiales" 12 . Agregando que "este impone al alumno la carga de estudiar de manera sistemática, clase a clase, porque es él quien protagoniza la respectiva sesión. El profesor queda relegado a la dirección del debate que

8 Figueroa Yáñez (2009), p. 267.

9 TAPIA (2008), p. 16.

10 Ibídem.

11 TAPIA (2008), p. 17.

12 González, Manuel. “Gonzalo Figueroa Yáñez, el académico y el hombre.”. En Fundación Fernando Fueyo Laneri. Estudios de Derecho Privado. Libre homenaje al Profesor Gonzalo Figueroa Yáñez. Santiago: Editorial Jurídica de Chile, 2008 , p. 28. 
debe generarse en el aula y luego cerrarlo, formulando sus conclusiones"13. Complementando que "el método empleado por Gonzalo Figueroa no sólo impone exigencias al alumno sino que también al profesor. Desde luego éste debe elaborar los materiales que habrán de utilizarse, lo que conlleva un amplio conocimiento bibliográfico y jurisprudencial, así como el estado en que se encuentra el debate doctrinario. La exigencia se extiende a la clase misma, sobre todo llegado el momento de esbozar, con pie en lo debatido y más allá de una minuta preconcebida, las conclusiones de rigor en la metodología empleada. Así el profesor, aparentemente pasivo durante la sesión, despliega un esfuerzo importante antes de ésta y al cerrar el debate, tarea que a la postre es superior a la de la clase magistral"'14.

Gonzalo Figueroa Yánez también fue un hombre público. Cumplía la célebre triada del siglo XX chileno: radical, masón y bombero. Hemos mencionado los dos últimos en las líneas anteriores. El hombre público escogió el partido Radical como consecuencia de sus convicciones liberales, de respeto y tolerancia. Esa misma creencia libertaria lo impulsó a oponerse a la Dictadura Militar (que inicialmente apoyó). Como él mismo señaló "mi conciencia no admitía una actitud de pasividad resignada frente a lo que estaba ocurriendo. [...] Como no tengo vocación de guerrillero [...] procuré integrarme a grupos o asociaciones que, con la utilización de las ideas, pudieran ir minando la fuerza del Gobierno Militar" "15. Así participó en el grupo de los 24 y de los 8 . El jurista intentó combinar la teoría con la praxis del derecho, trabajando por una nueva constitución para Chile. Empleando las herramientas de la abogacía, presentó una querella contra el general Augusto Pinochet por la compra de la casa ubicada en el Melocotón. Recordando que la pluma es más fuerte que la espada, no dudo en usarla para combatir al Régimen. En 1985, junto con Jorge Ovalle y otros próceres radicales, fundó la revista "Cauce". En sus números se denunció la corrupción del gobernante de facto, quien con recursos públicos, construía sus residencias en Lo Curro y El Melocotón, así como los negocios de "parientes y paniaguados del régimen", y las violaciones a los Derechos Humanos. Esa labor significó que la Dictadura lo encarcelara en 1986.

Con el regreso a la democracia, el hombre público pudo asumir una tarea vinculada a su condición docente. El presidente Patricio Aylwin lo envió como su representante ante la UNESCO en París (1990 - 1994).

Al retornar a Chile, asumió la Dirección de la Escuela de Postgrado, en ese entonces Escuela de Graduados-. Su primer período, que va desde 1995 a 1998, estuvo marcado por su interés en la formación de académicos. Ello se reflejó en el curso que impartió desde el 1995 hasta 2001, sobre Docencia Jurídica. 
Don Gonzalo vio en el Programa de Magíster en Derecho, la principal cantera de docentes en derecho.

Su obra de formación de docentes no se centró solo en su alma máter. Don Gonzalo, consciente de las necesidades del país, viajó incesantemente por las universidades de regiones, impartiendo cátedras y cursos de postgrado. Jorge TAPIA, profesor de derecho constitucional de la Universidad Arturo Prat, señala que la actividad de Gonzalo Figueroa se expandió al norte, impartiendo clases regulares de derecho civil en Arica, Iquique y Copiapó ${ }^{17}$. De esas experiencias, don Gonzalo constató que la enseñanza del derecho en regiones venía configurada por las realidades de Santiago. Sobre ello, proponía la reestructuración de la enseñanza del derecho de acuerdo a la realidad y características de la región ${ }^{16}$. También participó en la Universidad Diego Portales, siendo director de la Fundación Fernando Fueyo.

Podemos decir que sus últimos años los dedicó a la docencia. Reviviendo al filósofo que había en él, se dedicó al estudio de la bioética. Así fue como desde mediados de los '90 hasta el final de sus días, participó en congresos e instancias académicas, elaboró monografías y dictó conferencias sobre el tema.

En 2009 asumió por segunda vez la dirección de la Escuela de Postgrado de la Facultad de Derecho de la Universidad de Chile. Con sus experiencias creyó que debía reforzar la cantera de docentes que era el Magíster en Derecho de la Universidad de Chile. Apostó por la continuidad en los estudios entre el pregrado y el postgrado. Pero por sobre todo, se caracterizó por vivir sus convicciones de tolerancia y respeto. En tiempos de crisis en la Facultad de Derecho, fue un hombre que apostó por el diálogo y la integración. Jamás marginó a nadie por tener posturas diferentes. Su calidad humana y docente le valió la distinción Juvenal Hernández en 2009.

\section{SUS OBRAS}

Si hablamos de la obra de Gonzalo Figueroa Yáñez, podemos apreciar alrededor de 42 escritos, que él mismo distinguió entre libros, documentos y ponencias sobre derecho (35); monografías filosóficas, sociológicas, y de crítica literaria (7).

Destacan dentro de sus obras jurídicas: Curso de derecho Civil (Santiago, Editorial Jurídica de Chile, 1975, 1988, 1995, 2006); La asunción de deudas y la cesión de contrato (Santiago, Editorial Jurídica de Chile, 1984); El patrimonio (Santiago, Editorial Jurídica de Chile, 1991, 1997, 2008); Persona, Pareja y 
Familia (Santiago, Editorial Jurídica de Chile, 1995); Derecho Civil de la persona. Del genoma al nacimiento (Santiago, Editorial Jurídica de Chile, 2001).

Merece una mención especial El Patrimonio. Con esta obra, Gonzalo Figueroa recorre las instituciones del Derecho Civil. En su primera parte se refiere a las concepciones del patrimonio, recorriendo uno de los temas más complejos del derecho civil. En esta sección dialogó con otras instituciones como los derechos, los bienes, la herencia. Su intento es utilizar las doctrinas existentes para explicar diferentes instituciones de acuerdo a las figuras jurídicas conectadas con este atributo de la personalidad. Es así como la segunda parte aborda el derecho de prenda general y el de herencia, explicando que dichas instituciones se entienden mejor con la doctrina clásica. Luego retoma la doctrina objetiva, y explica las instituciones de la representación, autocontratación, la asunción de deudas, la cesión de contratos, la capacidad, la causa y el enriquecimiento sin causa, entre otros. Aborda el matrimonio cuando habla de los patrimonios de los cónyuges y el régimen de participación en los gananciales, pasando a los bienes familiares. Lo mismo hace con la sucesión por causa de muerte. Y estudia las personas jurídicas y sus respectivos patrimonios. Se trata de una obra sobre el derecho civil, que con maestría da guía haciendo alusión al patrimonio.

Por otro lado, nos encontramos con su lado visionario, cuando leemos Persona, pareja y familia. Ahí el jurista aparece para señalar los desafíos entre las regulaciones proporcionadas por el Código Civil, y cómo los avances en tecnología médica cuestionan las interpretaciones de dichos preceptos. También es un adelantado con la regulación de la pareja. Fiel a su liberalismo, sostiene que la familia de la Constitución es un término amplio que engloba tanto la que nace de un vínculo matrimonial, como aquellas que no. Luego se refiere a los hijos, abordando la filiación y el estatuto jurídico de los mismos. En este punto, como jurista, defiende la igualdad entre hijos, en una época en que ellos debían soportar las cargas de las decisiones de los padres. El libro, escrito a mediados de los '90, se enfrenta con la realidad de las "clases de hijos" en Chile, que tenían distintos derechos, dependiendo del vínculo existente entre sus progenitores. También aborda las concepciones de padre y madre. Ahí es claro en señalar que dichos vínculos no deben radicarse exclusivamente en la genética, sino que en la voluntad de hacer nacer una persona. Con ello, va más allá, abordando los temas de fecundación asistida, o de los vientres de alquiler.

\section{LA PARTIDA}

Don Gonzalo Figueroa Yáñez dejó este mundo el 7 de noviembre de 2011. Dicho día, la Escuela de Derecho no solo perdió un gran profesor, sino que también al testimonio viviente de los grandes cambios en la investigación y enseñanza. 